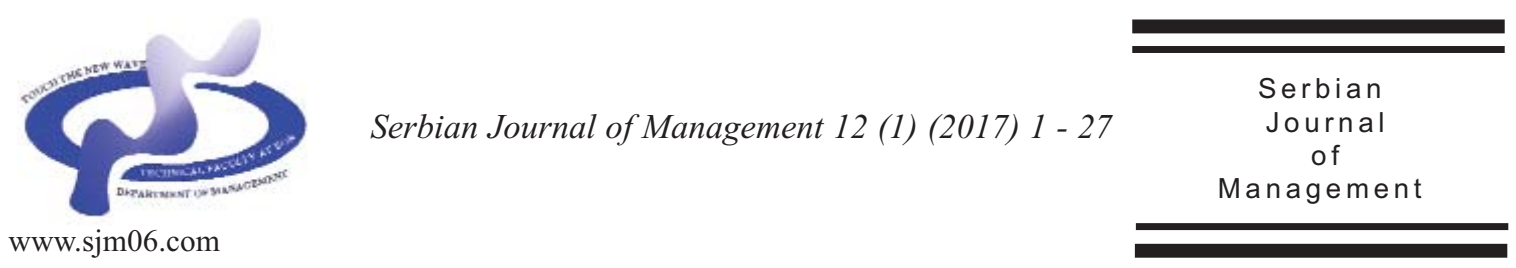

\title{
MULTI-CRITERIA DECISION MAKING: AN EXAMPLE OF SENSITIVITY ANALYSIS
}

\author{
Dragan S. Pamučar, Darko Božanić and Aca Ranđelović \\ University of defence in Belgrade, Military academy, \\ Pavla Jurišića Šturma 33, 11000 Belgrade
}

(Received 11 October 2015; accepted 02 July 2016)

\begin{abstract}
This study provides a model for result consistency evaluation of multicriterial decision making (MDM) methods and selection of the optimal one. The model is based on the analysis of results of MDM methods, that is, the analysis of changes in rankings of MDM methods that occur as a result of alterations in input parameters. In the recommended model, we examine sensitivity analysis of MDM methods to changes in criteria weight and result consistency of methods to changes in measurement scale and the way in which we formulate criteria. In the final phase of the model, we select the most suitable method to solve the observed problem and the optimal alternative. The model is tested on an example, when the optimal MDM method selection was required in order to determine the location of the logistical center. During the selection process, TOPSIS, COPRAS, VIKOR and ELECTRE methods were considered. VIKOR method demonstrated the biggest stability of rankings and was selected as the most fit method for ranking the locations of the logistical center. Results of the demonstrated analysis indicate sensitivity of standard MDM methods to criteria considered in this work. Therefore, it is necessary, to take into account stability of the considered method during the selection process of the optimal method.
\end{abstract}

Keywords: Multicriterial decision making methods, TOPSIS, COPRAS, VIKOR, ELECTRE

\section{INTRODUCTION}

Multicriterial Decision Making (MDM) methods are characterized by a particular mathematical apparatus because of which application of different methods on the same problem often results in different solutions. Consequentially, the alternative choice does not depend solely on the criteria that we use to evaluate those alternatives, but on the MDM method that we use as well. Due to the difference in numerical techniques of

\footnotetext{
* Corresponding author:dpamucar@gmail.com

DOI:10.5937/sjm12-9464
} 
methods, one can expect different ranking results, that is, different alternative choices. In accordance with that, as emphasized by Triantaphyllou and Mann (1989), there is a paradox present in the process of MDM method selection: "Which MDM method to use so that we use the best MDM method?"

In the last couple of years, there have been frequent comparative analyses by authors who conduct comparison of results gained through use of several different MDM methods (Rodrigues et al., 2014; Anojkumar et al., 2014; Liu et al, 2013; Wang \& Tzeng, 2012; Peng et al., 2011; Yang et al., 2008). However, the fact that there are multiple methods that recommend the same choice is not a satisfactory warranty of rationality and quality of the calculated solution (Pavličić, 1997). Because of cases when those results are not mutually consistent, there is a call for evaluation of stability of the calculated solution besides the use of multiple methods when solving MDM problems. A good indicator of stability of a calculated solution is the examination of changes in situations when value factors that are included in the MDM model are varied. In other words, MDM method selection needs to be objectified. Pamučar and Ćirović (2015) emphasize that objective MDM method selection implies defining criteria based on which rationality of calculated results would be evaluated, and that would enable comparison of related methods and selection of the optimal one. In that context, reliability of a method can be defined as the measure of trust of the decision maker in the results obtained by using that method.

It often happens that authors do not analyze solutions with multiple MDM methods and do not conduct sensitivity analysis (Chang, 2014; Ahari \& Niaki, 2014; Liu \& Wu, 2013; Morteza \& Farokh-Payam,
2015); instead, based on the results obtained by using a single method they make a selection of the optimal alternative. In other cases, like Kelemenis and Askounis (2010) or Bottani and Rizzi (2006), analysis of previously mentioned influence is not conducted; instead, comparison of applied procedures and obtained results with results obtained through other methods is conducted. Similar to this, Mulliner et al. (2013) did not compare results from COPRAS method with results obtained through other methods, nor did they conduct sensitivity or reliability analysis of methods, instead they referred to works in which it is possible to see comparison of results of use of different MDM methods.

Examples of analysis of ranking results accordance obtained through different methods can be seen in Rodrigues et al. (2014), Liu et al. (2013), Peng et al. (2011), Yang et al. (2008). It should be noted that results of this kind of research depend on the observed method choice and characteristics of problems that those methods are being applied to. In accordance with that, there are different conclusions made by different authors. In works in which robustness and stability analysis of obtained solution is conducted in MDM, besides comparison with solutions gained thorough other methods and techniques, analysis is often based on appropriate sensitivity analysis of results to changes of certain parameters in decision making model ( $\mathrm{Yu}$ et al., 2012; Stevens-Navarro et al., 2012; Li et al., 2013a; Li et al., 2013b; Corrente et al., 2014; Kannan et al., 2014).

Triantaphyllou and Mann emphasize two criteria for MDM methods analysis. First criterion refers to fulfillment of result consistency conditions in a case when a method, applied on a multi- 
dimensional problem, is applied on a singledimensional problem (i.e. problem in which there is only one unit of measurement), and the second criterion refers to the stability conditions of the best ranked alternative, in a case when some alternative (not the best one)is replaced by another worse alternative, whereby the weight coefficients of decision making attributes do not change. In their study, Triantaphyllou and Mann compared four methods (WSM-weighted sum model, WPM-weighted product model, AHPanalytic hierarchy process and Revised AHPrevised hierarchy process). Those two authors concluded that none of the considered methods is completely effective in terms of both evaluative criteria. In 1996, Triantaphyllou and Lin examined five fuzzy multi-attribute decision-making methods (fuzzyfied WSM, WPM, AHP, revised AHP and TOPSIS) in terms of the same two evaluative criteria, adapted to fuzzy environment. Just like the previous study, when four crisp methods were compared, they came to same conclusions: that none of the examined fuzzy methods is perfectly effective in terms of both evaluative criteria and that precision methods decrease with the increase of complexity of the decision making problem.

As specified in shown researches, selection of optimal MDM method is a very complex problem which without prior sensitivity analysis of the solution can have a wrong selection as a consequence if an MDM method which gives inconsistent solutions is used. Therefore, there is a need to define models for result consistency evaluation of methods of multicriterial decision making. Therefore, it si necessary to define the model for sensitivity analysis (evaluation of result consistency) of MDM methods. The main goal of the sensitivity analysis of the method presented in this work is to select such method that keeps the majority of priorities in scenarios during the change of weight coefficients and which keeps the rankings of alternatives in case of change of the measurement scale and change in the way the criteria is formulated. The model for sensitivity analysis of MDM methods presented in this work recommends a general procedure for the selection of the most suitable MDM method for the observed problem. The model was tested on the example of logistical center location selection and the results of are presented in section 5. It is necessary to emphasize that the results presented in section 5 refer only to the observed example of the logistical center location selection and cannot be generalized.

Model is displayed with two parts. The first one represents a model for consistency evaluation, and then its application is described. Application of a model is depicted on the example when logistical center location selection was made by using COPRAS, TOPSIS, VIKOR and ELECTRE methods. In the last part of the work, final considerations and recommendations for future research and advancement of the recommended model are given.

Before any further explanation of the recommended model, we are going to explain the basic setup of methods used in this work. Four methods were used: COPRAS, TOPSIS, VIKOR and ELECTRE.

\subsection{COPRAS method}

Ranking alternatives by the COPRAS method assumes direct and proportional dependence of significance and priority of investigated alternatives on a system of criteria (Ustinovichius et al., 2007). The selection of significance and priorities of 
alternatives, by using COPRAS method, can be expressed concisely using four stages (Ustinovichius et al., 2007; Viteikiene \& Zavadskas, 2007).

For normalization in COPRAS method the following formula is used:

$$
\tilde{x}_{i j}=\frac{x_{i j}}{\sum_{i=1}^{m} x_{i j}}
$$

where $x_{i j}$ is the performance of the $i$-th alternative with respect to the $j$-th criterion, $\tilde{x}_{i j}$ is its normalized value, and $m$ is the number of alternatives.

In COPRAS method, each alternative is described with the sum of maximizing attributes $\mathrm{S}_{+i}$, i.e. optimization direction is maximization, and minimizing criteria $\mathrm{S}_{-i}$, i.e. optimization direction is minimization. In order to simplify calculation of $\mathrm{S}_{+i}$ and $\mathrm{S}_{-i}$ in the decision-making matrix columns maximizing criteria are placed first, followed by the minimizing criteria. In such cases, $\mathrm{S}_{+i}$ and $\mathrm{S}_{-i}$ is calculated as follows:

$S_{+i}=\sum_{j=1}^{k} \tilde{x}_{i j} \cdot q_{j}$

$S_{-i}=\sum_{j=k+1}^{n} \tilde{x}_{i j} \cdot q_{j}$

In formulas (2) and (3), $k$ is the number of maximizing criteria; $n$ is total number of criteria; and $q_{j}$ is significance of the $j$-th criterion.

The relative weight $Q_{i}$ of $i$-th alternative is calculated as follows:

$$
Q_{i}=S_{+i}+\frac{\sum_{i=1}^{m} S_{-i}}{S_{-i} \sum_{i=1}^{m} \frac{1}{S_{-i}}}
$$

The priority order of compared alternatives is determined on the basis of their relative weight. The alternative with higher relative weight has higher priority (rank), and the alternative with the highest relative weight is the most acceptable alternative.

\subsection{TOPSIS method}

The TOPSIS method is one of the most widely used MDM methods. The basic principle of TOPSIS method is that the best alternative should have the shortest distance from the ideal solution and the farthest distance from the anti-ideal solution. A relative distance of each alternative from ideal and anti-ideal solution is obtained as

$$
Q_{i}=\frac{S_{i}^{-}}{S_{i}^{+}+S_{i}^{-}}, i=1, \ldots, n
$$

where $S_{i}^{+}$and $S_{i}^{-}$are separation measures of alternative $i$ from the ideal and anti-ideal solution, respectively; $Q_{i}$ is the relative distance of alternative $i$ to the ideal solution, and $Q_{i} \in[0,1]$.

The largest value of the criterion $Q_{i}$ correlates with the best alternative. Therefore, in TOPSIS method, the alternatives are ranked on the basis of their $Q_{i}$ in ascending order, and the alternative with the highest value of $Q_{i}$ is the best ranked. The best ranked, or the most preferable, alternative $A_{T P S}^{*}$ can be determined using the following formula:

$$
A_{T P S}^{*}\left\{A_{i}=\max _{i} Q_{i}\right\}
$$

The separation measures of each alternative, from the ideal and anti-ideal solution, are computed using following 
formulas:

$$
\begin{aligned}
& S^{+}=\left\{\sum_{j=1}^{n}\left[w_{j}\left(r_{i j}-r_{i}^{+}\right)\right]^{2}\right\}^{1 / 2} \\
& S^{-}=\left\{\sum_{j=1}^{n}\left[w_{j}\left(r_{i j}-r_{i}^{-}\right)\right]^{2}\right\}^{1 / 2}
\end{aligned}
$$

where element $r_{i j}$ represents the performance of alternative $A_{i}$ in relation to criterium $C_{j}$. For $m$ criteria $\left(C_{1}, C_{2}, \ldots C_{m}\right)$ and $n$ alternatives $\left(A_{1}, A_{2}, \ldots, A_{n}\right)$ matrix $R$ has the shape $\mathrm{R}=\left[r_{i j}\right]_{\text {nxm }}$.

Values $\left(w_{1}, w_{2}, \ldots, w_{m}\right)$ represent tweight values of criteria that satisfy the condition $\sum_{i=1}^{n} w_{i}$.

The ideal $A^{+}$and the anti-ideal $A^{-}$solution in TOPSIS method can be determined using the formula (8) and (9), respectively

$A^{+}=\left\{\left(\max v_{i j} \mid j \in G\right),\left(\min v_{i j}, j \in G^{\prime}\right), i=1, . ., n\right\}=\left\{v_{1}^{+}, v_{2}^{+}, \ldots, v_{m}^{+}\right\}$

$A^{-}=\left\{\left(\min v_{i j} \mid j \in G\right),\left(\max v_{i j}, j \in G^{\prime}\right), i=1, . ., n\right\}=\left\{v_{1}^{-}, v_{2}^{-}, \ldots, v_{m}^{-}\right\}$

It can be seen from the formula (6) and (7) that the ordinary TOPSIS method is based on the Euclidean distance. In addition to Euclidean distance, some examples are presented in literature where TOPSIS method was used with other metrics, especially with a city-block distance (Chang et al., 2010; Shanian \& Savadogo, 2006).

\subsection{VIKOR method}

VIKOR method represents an often used method for multicriterial ranking, suitable fo solving different decision-making problems. It is especially suitable for situations where criteria of quantitative nature are prevalent. VIKOR method was developed based on the elements of compromise programming. The method starts from the "border" forms of $L p$ metrics (Opricović \& Tzeng, 2004). It seeks the solution that is the closest to the ideal. In order to find the distance from the ideal point it uses the following function:

$L_{p}\left(F^{*}, F\right)=\left\{\sum_{j=1}^{n}\left[f_{j}^{*}-f_{j}(x)\right]^{p}\right\}^{1 / p}, 1 \leq p \leq \infty$

This function represents the distance between the ideal point $F^{*}$ and point $F(x)$ in space of criteria functions (Opricović \& Tzeng, 2004). The compromise solution is obtained by minimizing this function. Opricović and Tzeng (2004) state that $p$ has the role of the balancing factor between the overall benefit and and the maximum of individual deviation. Smaller values of $p$ emphasize the group benefit, while greater values of $p$ increase the weight given by individual deviations.

The essence of VIKOR method is that for every action it finds the value of $Q_{i}$, and then it chooses the action which has the lowest listed value (the smalles distance from the "ideal" point). The measurement for multicriterial ranking of the $i$-th action $\left(Q_{i}\right)$ is calculated from the equation:

$Q_{i}=v \cdot Q S_{i}+(1-v) Q R_{i}$

where

$Q S_{i}=\frac{S_{i}-S^{*}}{S^{-}-S^{*}}$

$Q R_{i}=\frac{R_{i}-R^{*}}{R^{-}-R^{*}}$

where $S^{*}=\min S_{j}, S^{-}=\max S_{j}, R^{*}=\min R_{\mathrm{j}}$ and $R^{-}=\max R_{j}$, while $S_{j}$ represents pessimistic solution, and $R_{j}$ the expected solution. 
By calculating values of $Q S_{i}, Q R_{i}$ and $Q_{i}$ for every action, three independent ranking lists can be formed. The size of $Q S_{i}$ represents the measurement of deviation through which the demand for maximal group benefit (the first ranking list) is expressed. The value of $Q R_{i}$ represents the measurement of deviation through which the demand for minimization of distance of some action from the "ideal" action (second ranking list) is expressed. The value of $Q_{i}$ represents the forming of compromise ranking list which ties together the values of $Q S_{i}$ and $Q R_{i}$ (the third ranking list). By choosing the smaller or the greater value for $v$ (the strategic weight of satisfying the majority of criteria), the decision-maker can factor the impact of the value of $Q S_{i}$ or the value of $Q R_{i}$ in the compromise ranking list. As the reliable ranking list by VIKOR method, we take the compromise ranking list with the value of $v=0.5$.

\subsection{ELECTRE method}

This is one of the first methods of the multicriterial ranking of alternatives. It has a broad application in practice when it comes to solving problems of inability to determine the strict domination of one action over the other (Wang \& Triantaphyllou, 2008; Triantaphyllou, 2000). In those cases, there is the necessity to bring in the so-called connections of the higher order, that is, defining criteria for "mechanical" ranking. In practice, the most common method is the method ELECTRE I, however, a few variations of this method have been developed as well, such as: ELECTRE II, ELECTRE III and ELECTRE IV. The similarity of all the modalities of this method is reflected in the same initial steps, and certain differences occur from the moment when the most acceptable alternative is to be selected.

ELECTRE method is based on comparing actions (alternatives) in pairs. It is necessary to meet two conditions (1) the condition of agreement - defined by the desired level of agreement and the real index of agreement and (2) the condition of disagreement defined by the desired level of disagreement and the real index of disagreement.

The agreement and disagreement indexes represent the quantitative pointers of agreement or disagreement that an alternative "a" can be ranked higher than the alternative "b", by all criteria at the same time. The first thing to examine is the degree of agreement between the weight preferences and paired connections of domination, followed by the degree of disagreement by which the evaluation of weight of certain actions is different. Because of that, this method is sometimes referred to as the analysis of agreement in literature. More details about the application process of this method can be found in (Wang \& Triantaphyllou, 2008; Rogers \& Bruen, 1998).

\section{MODEL FOR SENSITIVITY ANALYSIS (CONSISTENCY EVALUATION) OF MDM METHODS}

Objective selection of decision making procedure assumes defining criteria based on which rationality of its results could be evaluated, and at the same time it would enable comparison of related methods and the selection of the most rational one. In the general case, model for result consistency evaluation of MDM methods and the selection of the optimal one for the analyzed 
problem consists of two phases (Figure 1). First phase represents the decision making problem setting and the application of mathematical MDM methods on the observed problem. As the result of the first phase we get alternatives ranking based on MDM methods. Second phase examines sensitivity analysis of MDM methods to changes in weight of criteria and consistency of method solutions to changes in measurement scale and the way in which criteria are formulated. As a result of the second phase, the optimal MDM method is selected that meets the following conditions: (1) it keels the first-ranked priorities in the majority of scenarios during the change of weigh coefficients and (2) keeps the rankings of alternatives in case of change of the measurement scale and (3) keeps the ranking of alternatives in case of change in the way of criteria formulation. Sensitivity analysis result is the selection of the most favorable MDM method to solve the observed problem and select the optimal alternative.

First phase of "MDM method application" is different from one other situation and depends on the problem that is being solved, knowledge of persons who are applying methods etc. By analyzing works that have dealt with issues of sensitivity analysis one can conclude that second phase should consist of: 1) solution stability assessment in a case when weight of criteria is changed; 2) result consistency analysis

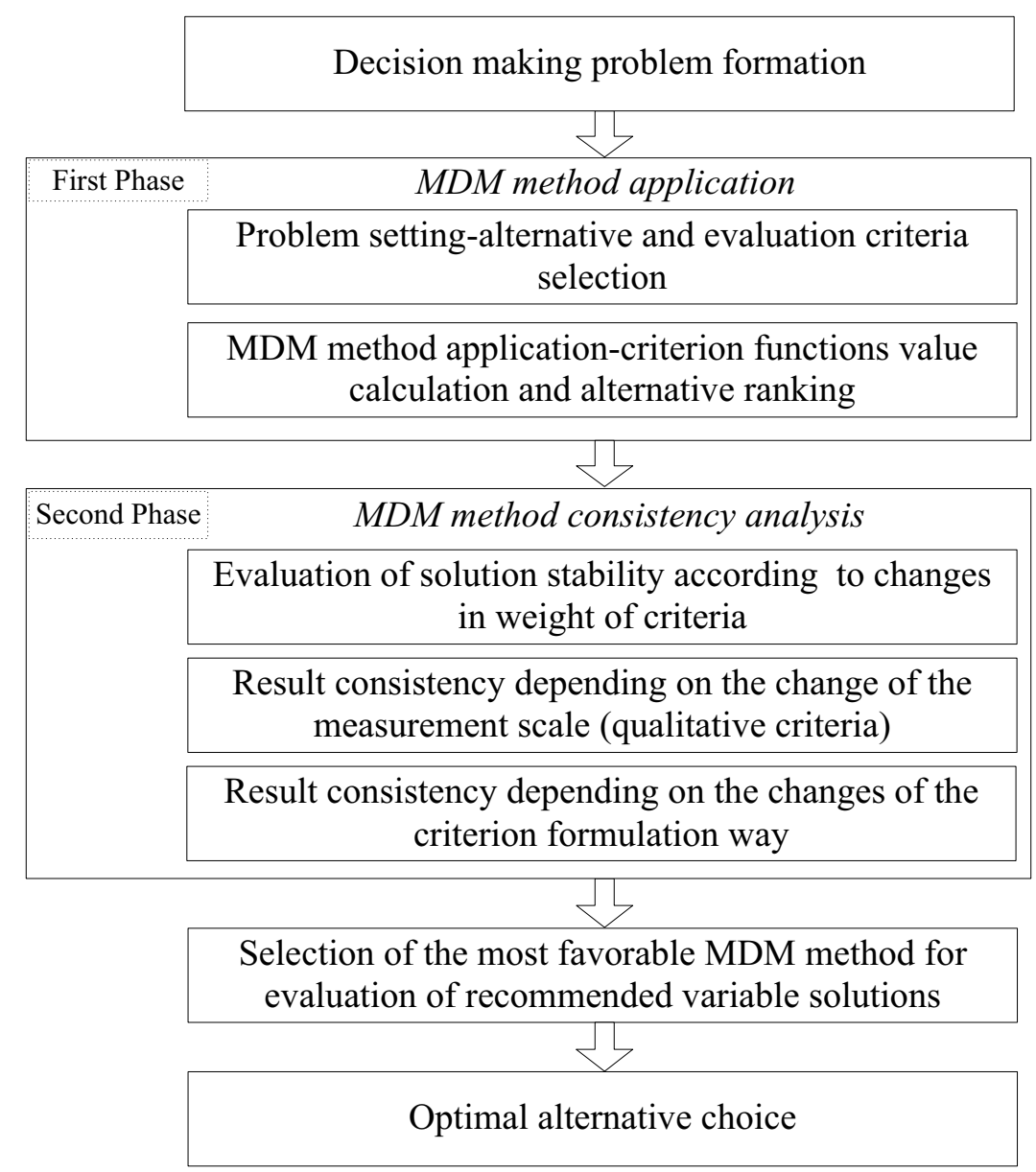

Figure 1. Model (algorithm) for evaluation of result consistency of MDM methods 
according to changes of measurement scale which is used to depict qualitative criteria and 3) result consistency analysis considering criteria formulation in a case when the same criterion can be shown in two normatively equivalent ways.

By consistency, we mean stability of results of MDM methods in case of change of measurement scale which are used to describe quantitative criteria and in case of change of the way criteria are formulated.

2.1. Stability of MDM methods solutions - The criteria weight change

Results of MDM methods mostly depend on the values of weight criteria coefficients, that is on the relative importance that we attribute to particular criteria. Sometimes final choices change with minor changes of weight criteria coefficients, due to that fact, MDM methods results are followed by an analysis of their sensitivity to these changes.

The goal of sensitivity analysis of MDM methods to changes of criteria weight is to determine the way in which changes of criteria weight lead to changes in alternative rakings. This kind of analysis can be used to confirm rankings which were obtained through mathematical models and selection of the optimal alternative. However, sensitivity analysis of MDM methods to changes of weight coefficients criteria is not enough to base our conclusions about the reliability of results given by MDM methods. Therefore, it is necessary to conduct consistency analysis of these results based on the changes of measurement units in which values of certain criteria are given and consistency analysis of results based on the formulation of criteria.
2.2. Stability of MDM methods solutions - The measurement scale change

Measurement scale independence (MSI) condition is formulated based on the so called independence of value scale condition which is applied in the normative theory of decision making in risk and uncertainty conditions (French, 1988).

French (1988) defined MSI condition for evaluation of procedure selection that we use to choose one action from a set of $m$ actions, $A_{i}, i=1,2, \ldots, m$ whose outcomes depend on $n$ possible circumstances $\theta_{j}, j=1,2, \ldots, n$. Value of the outcome of an action $A_{i}$ during the realization of circumstance $\theta_{j}$ is labeled as $v_{i j}$ and expressed in cardinal units of usefulness of the decision maker, that is, we measure it on an interval scale. We can measure cardinal values on different measurement scales, whereby outcome values are measured on two scales, $v_{i j}$ and $v_{i j}^{+}$, mutually connected by positive affine transformation.

$v_{i j}^{+}=a v_{i j}+b$

where $a$ and $b$ are constants under condition of $a>0$.

MSI condition in this work is adapted to needs of consistency analysis of MDM methods. By applying the decision making method that satisfies the MSI condition we get a consistent result, that is, a unique ranking list of alternatives independent from the scale that we used to measure their outcomes. Therefore, ranking result based on a certain MDM method must not depend on a measurement unit which we use to express the value of any attribute with the condition that different measurement unites of the observed attribute are mutually connected by 
a linear or positive affine transformation.

In other words, whether we measure length in meters, kilometers or miles, temperature in degrees Celsius or Fahrenheit, and income in euros or pounds, results obtained through MDM methods have to be the same. Also, whether we measure qualitative attributes on 1, 2, 3, 4, 5 scale or its positive affine transformation $y=2 x-1$, that is, on the $1,3,5,7,9$ scale, the final ranking list of alternatives must not change.

\subsection{Stability of MDM methods} solutions - The criteria formulation change

Criteria formulation independence (CFI) condition is formulated based on the descriptive invariability condition which is described in behavioral theory of decision making as the condition of choice rationality of an individual decision maker (Kahneman \& Tversky, 1981). If there are multiple ways to show alternatives and if these ways are mutually normatively equivalent, according to those alternatives, an individual's preferences should not depend on selected formulations, that is, they should be independent from so called frameworks (Pavličić, 2002).

Rational decision makers tend to choose the optimal alternative, that is, the one with the highest possible values of income criteria and the lowest possible values of expenditure criteria. If for example, production workers are evaluated based on the quality of production and achieved productivity, then the ranking list must not depend on the fact that the first criterion is formulated as "the percentage of working products" or as "the percentage of spoilage". Also, the ranking list must not depend on the fact that productivity is measured based on "the number of products in a unit of time" or "the time required to produce a single unit of product".

Results of experimental psychology show that this condition is often violated in practice. When we rephrase the alternatives shown in their positive framework to the negative framework, a phenomenon of reversed preferences occurs. The most famous example in literature is demonstrated during the selection of two therapies (A and B) in order to cure the same illness. Individual preferences towards those therapies change with the change of their outcome (Kahneman \& Tversky, 1979). When outcomes are expressed as survival outcomes (positive framework) majority of the examinees choose therapy A. When the same results are expressed in percentage of mortality (negative framework), most of the examinees choose therapy B. Because the mortality and survival percentages mutually add up to 100 (\% of mortality $=100-\%$ of survival) we can conclude that the two formulations are normatively equivalent, that is, they represent equally precise and identical descriptions of alternatives based on the content.

The decision makers during the formulation of criteria which we use to describe variant solutions are in a similar situation. So, for example, the criterion of speed of lifting/lowering weight can be represented as the expenditure criterion (negative framework) which is expressed as the time required for the crane to lift/lower the weight one meter. The same way, listed criteria can be represented as the income criterion (positive framework) expressed as the height on which a forklift needs to lift/lower the weight in one minute. Positive and negative framework are connected with 
a function $X_{j}^{-}=C / X_{j}^{+}$, where $C$ is a constant. It does not matter if the speed of lifting/lowering weight criterion is observed in positive or negative framework, the result (ranking) of a MDM method should be consistent (Pamučar \& Ćirović, 2015).

Pavličić (2002) emphasizes that the appearance of reversed preferences maintains irrationality of the decision maker who should reexamine his/her attitude towards the alternatives and before making the final decision eliminate the effect of the "framework" on the choice. From this, we can conclude that if we request this level of rationality from an individual decision maker, we need to make sure that the MDM methods we use as a way to support rational decision making satisfy the same condition.

\section{INITIAL RESULTS: APPLICAITON OF TOPSIS, COPRAS, VIKOR AND ELECTRE METHODS:}

Model for result consistency evaluation of a MDM method is tested on an example of the logistical center (LC) location selection. LC represents a unique technological, spatial, organizational and economical whole which combines different carriers and users of logistical services. With the selection of the optimal location of an LC, transportation expenses are lowered, business performance, competitiveness and profitability improve. The goal is to find a location which generates lowest expenses, offers highest efficiency and at the same time fulfills operational and strategic needs.

The LC location selection represents a procedure for selection of one of multiple possible solutions. A big number and heterogeneity of location factors clearly shows that the location problems are of interdisciplinary character and that they often require usage of complex procedures during the solution selection. There are multiple methodologies and procedures that are present in this area (Kaboli et al., 2007; Lai et al., 2010; Sun, 2012; Zare Mehrjerdi \& Nadizadeh, 2013; Rahmaniani et al., 2013). The selection of location for LC development is a problem that can be observed as a special case within the framework of general facility location problems. The facility location problem usually involves a set of locations (alternatives) which are evaluated against a set of weighted criteria independent from each other. The alternative that performs best with respect to all criteria is chosen for implementation.

Literature research in the area of facility location showed that location problems are usually solved by applying methods such as TOPSIS, COPRAS, VIKOR and ELECTRE (Chen \& Liu, 2006; Wang \& Liu, 2007; Ghoseiri \& Lessan, 2008; Kracka et al., 2010; Barysiene, 2012; Rezaeiniya et al., 2012). This is the reason why LC location choice is conducted by applying listed methods. By applying these MDM methods, initial solution was obtained and result consistency analysis was conducted. As a result of this analysis, methods which provided inconsistent results were eliminated and the optimal LC location was selected.

Multiple factors affect LC location choice, and at the base level they can be viewed as characteristics of the requests of logistical flows, characteristics of the LC, characteristics of the location and its surroundings. By analyzing literature (Kaboli et al., 2007; Ou \& Chou, 2009; Lai et al., 2010; Sun, 2012; Zare Mehrjerdi \& Nadizadeh, 2013; Rahmaniani et al., 2013), 
characteristics of the tri-modal LC and development on the Danube river. logistical flows, 11 criteria were identified Evaluation of qualitative criteria was based on which the location selection of trimodal LC is going to be conducted, Table 1. Weight coefficient of the criteria were obtained based on the literature analysis (Kaboli et al., 2007; Ou \& Chou, 2009; Lai et al., 2010; Sun, 2012; Zare Mehrjerdi \& Nadizadeh, 2013; Rahmaniani et al., 2013).

A total of eight locations were considered (Belgrade - LC 1, Pančevo - LC 2, Novi Sad - LC 3, Prahovo - LC 4, Smederevo - LC 5, Bogojevo - LC 6, Apatin - LC 7 and Apatin LC 8). Table 3. shows characteristics of eight locations (alternatives) for the tri-modal LC

conducted based on experiental knowledge of eight decision makers who are located on the position of operational managers of logistical centers. Fuzzificated Likert scale was used in order to evaluate the qualitative criteria (Camparo, 2013), as shown in Table 2.

In Table 3, next to the criteria labels, there was the type of criterion filed as well, where max marks criteria of the "benefit" type (bigger criterion value is preferable), whereas min marks criteria of the "cost" type (lower criterion value is preferable).

Table 1. Criteria for LC selection

\begin{tabular}{|c|c|c|c|}
\hline Criterion & Criterion name & $w_{i}$ & Unit of Measurement \\
\hline$C_{1}$ & Connectivity to Multimodal Transport & 0.109 & Linguistic Variable \\
\hline$C_{2}$ & Infrastucture Development Evaluation & 0.105 & $\begin{array}{l}\text { Infrastructure Development } \\
(\%)\end{array}$ \\
\hline$C_{3}$ & Environment effect & 0.101 & Linguistic Variable \\
\hline$C_{4}$ & $\begin{array}{l}\text { Conformity With Spatial Plans And Strategy Of } \\
\text { Economic Development }\end{array}$ & 0.097 & Linguistic Variable \\
\hline$C_{5}$ & Gravitating Intermodal Transport Unit - ITU & 0.094 & $\begin{array}{l}\text { Number of Gravitating ITUs } \\
\text { (ITU/year) }\end{array}$ \\
\hline$C_{6}$ & Reload capacity of an LC & 0.094 & $\begin{array}{l}\text { Number of Reloaded ITUs } \\
\text { (ITU/h) }\end{array}$ \\
\hline$C_{7}$ & $\begin{array}{l}\text { Available Area For Future Development And Capacity } \\
\text { Expansion Of Lcs }\end{array}$ & 0.093 & LC Development Area $\left(\mathrm{m}^{2}\right)$ \\
\hline$C_{8}$ & User's Distance From an LC & 0.088 & Linguistic Variable \\
\hline$C_{9}$ & Traffic Safety & 0.084 & Linguistic Variable \\
\hline$C_{10}$ & Length of Railroad Reload Front & 0.071 & Reload Front Length (m) \\
\hline$C_{11}$ & $\begin{array}{l}\text { Evaluation of Quality of Traffic Approaches For } \\
\text { Interimpellant Means of Transportation }\end{array}$ & 0.063 & Linguistic Variable \\
\hline
\end{tabular}

Table 2. Fuzzificated Likert Scale for Alternative evaluation

\begin{tabular}{cll}
\hline No. & Linguistic terms & Triangular fuzzy numbers \\
\hline 1. & Very good $(\mathrm{VG})$ & $(4.5,5,5)$ \\
2. & Good $(\mathrm{G})$ & $(3.5,4,4.5)$ \\
3. & Fair $(\mathrm{F})$ & $(2.5,3,3.5)$ \\
4. & Poor $(\mathrm{P})$ & $(1.5,2,2.5)$ \\
5. & Very poor $(\mathrm{VP})$ & $(1,1,1)$ \\
\hline
\end{tabular}


Table 3. Evaluation of Considered LC Locations

\begin{tabular}{|c|c|c|c|c|c|c|c|c|c|c|c|}
\hline \multirow[b]{2}{*}{ Alternative } & \multicolumn{11}{|c|}{ Criteria } \\
\hline & $\begin{array}{l}C_{l} \\
(\max )\end{array}$ & $\begin{array}{l}C_{2} \\
(\max )\end{array}$ & $\begin{array}{l}C_{3} \\
(\mathrm{~min})\end{array}$ & $\begin{array}{l}C_{4} \\
(\max )\end{array}$ & $\begin{array}{l}C_{5} \\
(\max )\end{array}$ & $\begin{array}{l}C_{6} \\
(\max )\end{array}$ & $\begin{array}{l}C_{7} \\
(\max )\end{array}$ & $\begin{array}{l}C_{8} \\
(\mathrm{~min})\end{array}$ & $\begin{array}{l}C_{9} \\
(\max )\end{array}$ & $\begin{array}{l}C_{10} \\
(\max )\end{array}$ & $\begin{array}{l}C_{11} \\
(\max )\end{array}$ \\
\hline LC 1 & G & $71 \%$ & G & $\mathrm{F}$ & 45000 & 150 & 1056 & $\mathrm{P}$ & $\mathrm{G}$ & 478 & G \\
\hline LC 2 & G & $85 \%$ & G & G & 58000 & 145 & 2680 & $\mathrm{P}$ & VG & 564 & G \\
\hline LC 3 & G & $76 \%$ & G & G & 56000 & 135 & 1230 & $\mathrm{P}$ & G & 620 & $\mathrm{~F}$ \\
\hline LC 4 & $\mathrm{~F}$ & $74 \%$ & $\mathrm{P}$ & G & 42000 & 160 & 1480 & G & $\mathrm{F}$ & 448 & VG \\
\hline LC 5 & VG & $82 \%$ & $\mathrm{~F}$ & VG & 62000 & 183 & 1350 & $\mathrm{P}$ & $\mathrm{G}$ & 615 & $\mathrm{G}$ \\
\hline LC 6 & G & $81 \%$ & $\mathrm{~F}$ & VG & 60000 & 178 & 2065 & $\mathrm{P}$ & $\mathrm{F}$ & 580 & G \\
\hline LC 7 & G & $80 \%$ & $\mathrm{~F}$ & VG & 59000 & 160 & 1650 & $\mathrm{~F}$ & VG & 610 & G \\
\hline LC 8 & $\mathrm{~F}$ & $82 \%$ & $\mathrm{G}$ & $\mathrm{G}$ & 54000 & 120 & 2135 & $\mathrm{~F}$ & $\mathrm{G}$ & 462 & VG \\
\hline
\end{tabular}

Defuzzification of the triangular fuzzy numbers which were used to describe qualitative criteria was conducted by applying expression (1) (Awasthi et al., 2013).

$A=\left[\left(a^{(r)}-a^{(l)}\right)+\left(a^{(m)}-a^{(l)}\right)\right] \cdot 3^{-1}+a^{(l)}$

Where $a^{(l)}$ and $a^{(r)}$ respectively represent the left and the right confidence interval

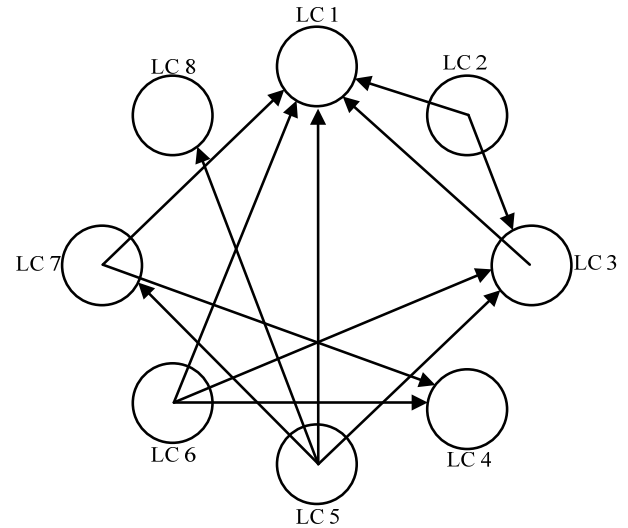

Figure 2. Domination of Alternatives by ELECTRE Method

Table 4. Initial Alternative Ranking

\begin{tabular}{lllllll}
\hline Alternative & \multicolumn{2}{c}{ TOPSIS } & \multicolumn{2}{c}{ COPRAS } & \multicolumn{2}{c}{ VIKOR } \\
\hline LC 1 & 0.3871 & 7 & 81.26 & 8 & 0,9600 & 7 \\
LC 2 & 0.6328 & 2 & 97.74 & 3 & 0,5323 & 4 \\
LC 3 & 0.4339 & 6 & 85.98 & 5 & 0,7636 & 5 \\
LC 4 & 0.3796 & 8 & 81.57 & 7 & 0,9674 & 8 \\
LC 5 & 0.6039 & 3 & 100.0 & 1 & 0,1717 & 2 \\
LC 6 & 0.6329 & 1 & 97.96 & 2 & 0,3470 & 3 \\
LC 7 & 0.5567 & 4 & 95.19 & 4 & 0,1076 & 1 \\
LC 8 & 0.4350 & 5 & 85.76 & 6 & 0,8802 & 6 \\
\hline
\end{tabular}

distribution of the triangular fuzzy number, represents initial value in which the triangular function reaches its maximum value.

Following the formation of the initial decision making matrix (Table 3), by applying TOPSIS, COPRAS, VIKOR and ELECTRE methods, alternative ranking was conducted. The alternative ranking by TOPSIS, COPRAS and VIKOR methods is shown in Table 4. Domination of alternatives by ELECTRE method is shown in Figure 2.

Based on Figure 2, we get alternative ranking based on ELECTRE method: LC $5>$ LC $6>$ LC $2>$ LC $7>$ LC $3>$ LC $8>$ LC 4 $>$ LC 1. In Table 4 , values of criteria functions are shown as well as alternatives ranking obtained through observed methods. Results show that different methods give different alternative rankings.

By COPRAS and ELECTRE methods, the greatest domination was demonstrated by alternative 5. However, VIKOR method 
favors alternative 7 (LC 7), whilst TOPSIS method favors alternative 6 (LC). These results confirm the attitude that the final choice is not determined exclusively by alternatives' characteristics, but the method used as well. This demonstrates the need to eliminate arbitrariness from the MDM selection phase, that is, to objectify the method selection process.

\section{MDM METHODS SENSITIVITY ANALYSIS PRESENTATION:}

In the following part of the work, based on the recommended model we analyzed the stability of solutions of the listed methods in case of change of the weight criteria, the change of the measurement scale and the change in the way criteria are formulated. The goal of sensitivity analysis of MDM methods by scenarios presented in this section is the selection of MDM method that maintains the priorities in the majority of scenarios during the change in weight coefficients and that maintains the ranking of alternatives in case of change of the measurement scale, that is in case of change in the way criteria is formulated.

\subsection{Change of Criteria Weights}

Results of MDM methods mostly depend on relative importance that we attribute to certain criteria. Sometimes alternatives' rankings change with very small changes of weight coefficients, because of what MDM results are followed by the analysis of their sensitivity to these changes.

A sensitivity analysis was performed to assess how changes in the weights assigned to the criteria would change the ranking of the alternatives. Sensitivity analysis is shown through 8 scenarios (Table 5), which show sensitivity analysis by favoritism of certain criteria.

\subsection{Change of Measurement Scale}

Measurement scale independence (MSI) is formulated based on an example used in normative theory of decision making in conditions of risk and uncertainty (French, 1988). In this work, MSI condition was adapted to the needs of solution consistency analysis of chosen MDM methods (TOPSIS, COPRAS, VIKOR and ELECTRE).

MSI condition implies that results gained through the use of MDM methods do not depend on the measurement unit that we use to express the value of any criterion under

Table 5. Scenarios with Different Criteria Weights and Preferences by Certain Alternatives Selections

\begin{tabular}{|c|c|c|c|c|c|c|c|c|c|c|c|c|}
\hline \multicolumn{2}{|c|}{ Scenarios } & \multicolumn{11}{|c|}{ Criterion Weight } \\
\hline & & $C_{I}$ & $C_{2}$ & $C_{3}$ & $C_{4}$ & $C_{5}$ & $C_{6}$ & $C_{7}$ & $C_{8}$ & $C_{9}$ & $C_{10}$ & $C_{11}$ \\
\hline S-1) & Uniform Weight Criteria & 0.091 & 0.091 & 0.091 & 0.091 & 0.091 & 0.091 & 0.091 & 0.091 & 0.091 & 0.091 & 0.091 \\
\hline S-3) & Priority of Criterion $\mathrm{C} 2$ & 0.068 & 0.320 & 0.068 & 0.068 & 0.068 & 0.068 & 0.068 & 0.068 & 0.068 & 0.068 & 0.068 \\
\hline S-4) & Priority of Criteria $\mathrm{C} 3$ and $\mathrm{C} 4$ & 0.067 & 0.067 & 0.200 & 0.200 & 0.067 & 0.067 & 0.067 & 0.067 & 0.066 & 0.066 & 0.066 \\
\hline S-6) & Priority of Criteria $\mathrm{C} 7$ and $\mathrm{C} 8$ & 0.067 & 0.067 & 0.067 & 0.067 & 0.067 & 0.067 & 0.200 & 0.200 & 0.066 & 0.066 & 0.066 \\
\hline S-7) & Priority of Criteria $\mathrm{C} 9$ and $\mathrm{C} 10$ & 0.050 & 0.050 & 0.050 & 0.050 & 0.050 & 0.050 & 0.050 & 0.050 & 0.350 & 0.200 & 0.050 \\
\hline S-8) & Priority of Criterion C11 & 0.065 & 0.065 & 0.065 & 0.065 & 0.065 & 0.065 & 0.065 & 0.065 & 0.065 & 0.065 & 0.350 \\
\hline
\end{tabular}


the condition that different units of measurement of the observed criterion are mutually interconnected by a linear or a positive affine transformation (Bach \& Bridy, 2013). In other words, whether or not the qualitative criteria is measured on the scale of $1,2,3,4,5$ or its positive affine transformation $y=2 x-1$, that is, on the scale of $1,3,5,7,9$, the final ranking list of alternatives must not change.

For the needs of this analysis, the initial Likert scale was modified (Table 6) and thus produced the second scale (Scale 2) which is connected with Scale 1by the positive affine transformation $(y=2 x-1)$. Scales $1(\mathrm{~S} 1)$ and 2 (S2) are shown in Table 6.

Scale $\mathrm{S} 2$ was used to describe qualitative criteria $C_{1}, C_{3}, C_{4}, C_{8}, C_{9}$ and $C_{11}$. Following that, comparison of results was conducted (of alternative rankings) which were obtained by using S1 and S2. Weight of criteria did not change. The values of remaining criteria $C_{2}, C_{5}, C_{6}, C_{7}$ and $C_{10}$ remained unchanged.

\subsection{Change in Formulation Criteria}

Criteria formulation independence (CFI) condition is formulated based on the descriptive invariability condition which is described in behavioral theory of decision making as the condition of choice rationality of an individual decision maker (Kahneman $\&$ Tversky, 1981). If there are multiple ways to show alternatives and if these ways are mutually normatively equivalent, according to those alternatives, an individual's preferences should not depend on selected formulations, that is, they should be independent from so called frameworks. Results of experimental psychology show that this condition is often violated in practice (Kahneman \& Tversky, 1979).

If we request this level of rationality from an individual decision maker, than MDM methods that we use as a support to rational decision making should also satisfy the condition. Since some criteria can be shown in both frameworks (income and expenditure), income formulation (benefit criteria) will often be treated as "the positive framework", whilst expenditure formulation (cost criteria) will be observed as "the negative framework" of criteria. Thereby it is a necessity that the MDM methods results are resistant to changes in formulation of these criteria.

criteria that can be represented in both ways. In this work, there are three criteria that are identified as the ones that can be shown in two normatively equivalent ways, that is, as income and expenditure criteria. These criteria are Evaluation of Infrastructure Development $\left(C_{2}\right)$, Reload capacity of an LC $\left(C_{6}\right)$ and Length of Railroad Reload Front $\left(C_{10}\right)$.

Criterion $C_{2}$ is expressed in percentages that are used to evaluate development of infrastructure. Based on that, $C_{2}$ can be expressd as an income criterion (\% degree of infrastructure development) as well as the expenditure criterion $(\%$ degree of

Table 6. Scales $S 1$ and $S 2$

\begin{tabular}{clll}
\hline No. & Linguistic terms & S1 & S2 \\
\hline 1. & Very good (VG) & $(4.5,5.5)$ & $(8.9 .9)$ \\
2. & Good (G) & $(3.5,4,4.5)$ & $(6,7,8)$ \\
3. & Fair (F) & $(2.5,3,3.5)$ & $(4,5,6)$ \\
4. & Poor (P) & $(1.5,2,2.5)$ & $(2,3,4)$ \\
5. & Very poor (VP) & $(1,1,1)$ & $(1,1,1)$ \\
\hline
\end{tabular}


infrastructure undevelopment). Due to the fact that the degree of infrastructure development and infrastructure undevelopment add up to $100 \%\left(X^{+}+X^{-}=\right.$ $100 \%)$, the two formulations are normatively equivalent. We use $X^{+}$to mark the degree of infrastructure development (\%), whilst we use $X^{-}$to mark the degree of infrastructure undevelopment (\%).

Criterion $C_{6}$ can be expressed as an income criterion (maximum number of ITUs that can be reloaded in an hour, ITU/h) and as an expenditure criterion (time required for ITU reload). Numerical values of these two formulations are connected with the function $X^{-}=60 / X^{+}$, where we use $X^{+}$to mark the maximal number of ITUs that can be reloaded in an hour (ITU/h), whilst we use $X^{-}$ to mark the time required to reload a single ITU (min/ITU).

Criterion Length of Railroad Reload Front $\left(C_{10}\right)$. Maximal required length of railroad front for reload is 720 meters. Based on this information $C_{10}$ can be expressed as an income criterion (existing length of the railroad reload front) and as an expenditure criterion (missing length of the railroad reload front). Since the existing length of the railroad reload front is supplemented by the missing length to $720\left(X^{+}+X^{-}=720\right)$, the two formulations are normatively equivalent. We mark the existing length of the front with $X^{+}$, and the missing length with $X^{-}$.

In analysis conducted in this work, we considered seven scenarios. Description of scenarios and results are shown in the next portion.

Scenario 1. Comparison of MDM methods results was conducted when criterion $\mathrm{C}_{2}$ was the income criterion (Scale
1-S1) and the expenditure criterion (Scale 1S1). The values of the remaining criteria are unchanged. Results of the MDM methods consistency through application of conditions from Scenario 1 are shown in Table A1, Appendix A.

Scenario 2. Comparison of MDM methods results was conducted when criterion $C_{6}$ was the income criterion (Scale 1 - S1) and the expenditure criterion (Scale 1 - S1). The values of the remaining criteria, just like in the previous scenario, remained unchanged. Results of the MDM methods consistency through application of conditions from Scenario 2 are shown in Table A2 (Appendix A).

Scenario 3. Comparison of MDM methods results was conducted when criterion $C_{10}$ was the income criterion (Scale 1 - S1) and the expenditure criterion (Scale 2 - S2). Values of other criteria remained unchanged. Results of the MDM methods consistency through application of conditions from Scenario 3 are shown in Table A3, Appendix A.

Scenario 4. Scenario 4 represents the synthesis of scenarios 1 and 2. Comparison of MDM methods results was conducted when criteria $C_{2}$ and $C_{6}$ were the expenditure criteria (Scale 2 - S2). The values of other criteria, just like in previous cases, remained unchanged. Obtained results were compared with results that were obtained when criteria $C_{2}$ and $C_{6}$ were represented as income criteria (Scale 1 - S1). Results of consistency analysis of MDM methods by applying conditions from Scenario 4 are shown in Table A4, Appendix A. 
Scenario 5. Scenario 5 represents the synthesis of scenarios 1 and 3. Comparison of MDM methods results was conducted when criteria $C_{2}$ and $C_{10}$ were the expenditure criteria (Scale 2 - S2). The values of the other criteria, just like in the previous cases, remained unchanged. Obtained results were compared with results that were obtained when criteria $C_{2}$ and $C_{10}$ were represented as income criteria (Scale 1 - S1). Results of consistency analysis of MDM methods by applying conditions from Scenario 5 are shown in Table A5, Appendix A.

Scenario 6. Scenario 6 represents the synthesis of scenarios 2 and 3. Comparison of MDM methods results was conducted when criteria $C_{6}$ and $C_{10}$ were the expenditure criteria (Scale 2 - S2). The values of the other criteria, just like in previous cases, remained unchanged. Obtained results were compared with results that were obtained when criteria $C_{6}$ and $C_{10}$ were represented as income criteria (Scale 1S1). Results of consistency analysis of MDM methods by applying conditions from Scenario 6 are shown in Table A6, Appendix A.

Scenario 7. Scenario 7 represents the synthesis of scenarios 1, 2 and 3 . Comparison of MDM methods results was conducted when criteria $C_{2}, C_{6}$ and $C_{10}$ were the expenditure criteria (Scale 2-S2). The values of the other criteria, just like in the previous cases, remained unchanged. Obtained results were compared with results that were obtained when criteria $C_{2}, C_{6}$ and $C_{10}$ were represented as income criteria (Scale 1-S1). Results of consistency analysis of MDM methods by applying conditions from Scenario 7 are shown in Table A7, Appendix A.

\section{RESULTS OF SENSITIVITY ANALYSIS OF MDM METHODS}

In the next part, we demonstrated the sensitivity analysis of TOPSIS, COPRAS, VIKOR and ELECTRE methods by scenarios described in the previous section (section 5).

\subsection{Results of sensitivity analysis of MDM methods to change in criteria weight}

Alternatives' ranking by scenarios is shown in Tables 7-10. Results show that assigning different weights to criteria leads to changes in rankings of alternatives, which show sensitivity of methods to changes of weight coefficients of criteria.

By comparing first-ranked alternatives by TOPSIS method in scenarios 1-8 with results shown in Table 4, we notice that in five out of eight scenarios, alternative six is ranked either as the first or the second alternative. This confirms domination of alternative 6 which was shown in Table 4.

Comparison of alternatives ranking shown in Tables 4 and 8 demonstrates that COPRAS method maintained favoring alternative 5 , because alternative 5 is ranked first in six out of eight scenarios.

VIKOR method in Table 4 has alternatives 7 and 5 respectively as the two first-ranked alternatives. With changes in weight of criteria by scenarios, alternative ranking changes significantly (Table 9). However, in six out of eight scenarios, alternative 5 was the first-ranked or the second-ranked alternative, whilst alternative 
Table 7. Alternatives Ranking for Different Weight Criteria Scenarios (TOPSIS)

\begin{tabular}{lllllllll}
\hline \multirow{2}{*}{ Alternative } & \multicolumn{7}{c}{ Alternatives Ranking by Scenarios } \\
\cline { 2 - 8 } & S-1 & S-2 & S-3 & S-4 & S-5 & S-6 & S-7 & S-8 \\
\hline LC 1 & 7 & 6 & 8 & 8 & 8 & 7 & 6 & 7 \\
LC 2 & 1 & 2 & 1 & 5 & 4 & 1 & 2 & 3 \\
LC 3 & 6 & 5 & 6 & 7 & 5 & 5 & 4 & 8 \\
LC 4 & 8 & 8 & 7 & 4 & 6 & 8 & 8 & 2 \\
LC 5 & 3 & 1 & 3 & 2 & 2 & 4 & 3 & 5 \\
LC 6 & 2 & 3 & 2 & 1 & 1 & 2 & 7 & 4 \\
LC 7 & 4 & 4 & 4 & 3 & 3 & 6 & 1 & 6 \\
LC 8 & 5 & 7 & 5 & 6 & 7 & 3 & 5 & 1 \\
\hline
\end{tabular}

Table 8. Alternatives Ranking for Different Weight Criteria Scenarios (COPRAS)

\begin{tabular}{lllllllll}
\hline \multirow{2}{*}{ Alternative } & \multicolumn{7}{c}{ Alternatives Ranking by Scenarios } \\
\cline { 2 - 8 } & S-1 & S-2 & S-3 & S-4 & S-5 & S-6 & S-7 & S-8 \\
\hline LC 1 & 8 & 6 & 8 & 8 & 8 & 7 & 7 & 7 \\
LC 2 & 2 & 2 & 2 & 4 & 4 & 1 & 1 & 2 \\
LC 3 & 6 & 5 & 6 & 7 & 5 & 6 & 4 & 8 \\
LC 4 & 7 & 8 & 7 & 5 & 7 & 8 & 8 & 6 \\
LC 5 & 1 & 1 & 1 & 1 & 1 & 3 & 3 & 1 \\
LC 6 & 3 & 3 & 3 & 2 & 2 & 2 & 5 & 3 \\
LC 7 & 4 & 4 & 4 & 3 & 3 & 4 & 2 & 5 \\
LC 8 & 5 & 7 & 5 & 6 & 6 & 5 & 6 & 4 \\
\hline
\end{tabular}

Table 9. Alternatives Ranking for Different Weight Criteria Scenarios (VIKOR)

\begin{tabular}{lllllllll}
\hline \multirow{2}{*}{ Alternative } & \multicolumn{7}{c}{ Alternatives Ranking by Scenarios } \\
\cline { 2 - 8 } & S-1 & S-2 & S-3 & S-4 & S-5 & S-6 & S-7 & S-8 \\
\hline LC 1 & 8 & 6 & 8 & 8 & 6 & 7 & 6 & 7 \\
LC 2 & 4 & 4 & 2 & 5 & 4 & 1 & 2 & 6 \\
LC 3 & 5 & 5 & 6 & 6 & 5 & 6 & 4 & 8 \\
LC 4 & 7 & 8 & 7 & 4 & 8 & 8 & 8 & 3 \\
LC 5 & 2 & 1 & 1 & 1 & 1 & 4 & 3 & 2 \\
LC 6 & 3 & 3 & 3 & 2 & 2 & 2 & 7 & 5 \\
LC 7 & 1 & 2 & 4 & 3 & 3 & 3 & 1 & 4 \\
LC 8 & 6 & 7 & 5 & 7 & 7 & 5 & 5 & 1 \\
\hline
\end{tabular}

Table 10. Alternatives Ranking for Different Weight Criteria Scenarios (ELECTRE)

\begin{tabular}{lllllllll}
\hline \multirow{2}{*}{ Alternative } & \multicolumn{7}{c}{ Alternatives Ranking by Scenarios } \\
\cline { 2 - 9 } & S-1 & S-2 & S-3 & S-4 & S-5 & S-6 & S-7 & S-8 \\
\hline LC 1 & 5 & 4 & 6 & 5 & 5 & 4 & 5 & 4 \\
LC 2 & 3 & 2 & 2 & 2 & 3 & 1 & 3 & 2 \\
LC 3 & 4 & 4 & 5 & 4 & 4 & 4 & 4 & 4 \\
LC 4 & 5 & 4 & 6 & 5 & 5 & 4 & 5 & 4 \\
LC 5 & 1 & 1 & 1 & 1 & 1 & 2 & 1 & 1 \\
LC 6 & 2 & 2 & 3 & 3 & 2 & 1 & 2 & 2 \\
LC 7 & 3 & 3 & 4 & 3 & 3 & 3 & 3 & 3 \\
LC 8 & 4 & 4 & 6 & 5 & 5 & 3 & 4 & 4 \\
\hline
\end{tabular}

7 was ranked first or second in three alternatives, as well as the small difference in scenarios. This demonstrates the domination values of criteria functions between the two of alternatives 5 and 7 compared to other listed alternatives. 
By comparing alternatives ranking shown in Figure 2 and Table 10 it was demonstrated that ELECTRE method maintained favoritism towards alternative 5 , as a result of alternative 5 being first or second ranked in all eight scenarios.

Sensitivity analysis of TOPSIS, COPRAS, VIKOR and ELECTRE methods showed that methods were sensitive to changes in weight and that they keep priorities of alternatives that were shown in Table 4. Methods COPRAS and ELECTRE favor alternative 5 , TOPSIS method favors alternative 6 , whilst VIKOR method favors alternative 7 . Based on the rankings obtained by using these four methods, the decision maker is being suggested to choose alternative 5 (it was first-ranked by two methods, second-ranked by one and thirdranked by one) or alternative 6 (it was firstranked by one method, second-ranked by two methods and third-ranked by one). Therefore, alternatives 5 and 6 are clearly dominant compared to other alternatives.

5.2. Results of sensitivity analysis of MDM methods to the change of measurement scale

Consistency of alternative rankings to changes in measurement scale are shown in Table 11. Consistency of rankings by ELECTRE method is shown on Figure 3. In
Table 11, below the scale label (S1 and S2), values of criteria functions were shown as well as the alternatives ranking which were obtained through the use of analyzed MDM methods.

Results shown in Table 11 and Figure 3 demonstrate that COPRAS, TOPSIS and ELECTRE methods do not give consistent solutions. Listed methods show inconsistency of rankings, that is, dependence of the final alternative ranking on the changes in measurement scale. VIKOR method gives consistent solutions, that is, changes in measurement scale do not affect the final ranking of alternatives. Shaded parts of Table 11 show inconsistent rankings. Using scale 1 with TOPSIS method causes changes in order of the second-ranked and third-ranked alternatives, as well as changes in order of the last ranked alternatives. Scale change at COPRAS method causes change in the order of the last ranked alternatives, whilst at ELECTRE method, the change of scale leads to significant change in alternative domination (Figure 3a and 3b). Marked in grey on Figure $3 \mathrm{~b}$ are alternatives which experience change in domination at ELECTRE method.

Results show that COPRAS, TOPSIS and ELECTRE methods violate MSI condition because their results change with the change of measurement unit in which values of qualitative criteria were expressed. On the

\section{Table 11. MSI-Alternatives Ranking}

\begin{tabular}{|c|c|c|c|c|c|c|c|c|c|c|c|c|}
\hline \multirow[t]{2}{*}{ Alternative } & \multicolumn{4}{|c|}{ COPRAS } & \multicolumn{4}{|c|}{ TOPSIS } & \multicolumn{4}{|c|}{ VIKOR } \\
\hline & S1 & & $\mathrm{S} 2$ & & S1 & & $\mathrm{S} 2$ & & S1 & & $\mathrm{S} 2$ & \\
\hline LC 1 & 81.26 & 8 & 79.89 & 7 & 0.3871 & 7 & 0.4141 & 7 & 0.9600 & 7 & 0.9600 & 7 \\
\hline LC 2 & 97.74 & 3 & 96.70 & 3 & 0.6328 & 2 & 0.6230 & 3 & 0.5323 & 4 & 0.5323 & 4 \\
\hline LC 3 & 85.98 & 5 & 84.63 & 5 & 0.4339 & 6 & 0.4550 & 5 & 0.7636 & 5 & 0.7636 & 5 \\
\hline LC 4 & 81.57 & 7 & 79.46 & 8 & 0.3796 & 8 & 0.3823 & 8 & 0.9674 & 8 & 0.9674 & 8 \\
\hline LC 5 & 100.0 & 1 & 100.0 & 1 & 0.6039 & 3 & 0.6252 & 2 & 0.1717 & 2 & 0.1717 & 2 \\
\hline LC 6 & 97.96 & 2 & 97.34 & 2 & 0.6329 & 1 & 0.6340 & 1 & 0.3470 & 3 & 0.3470 & 3 \\
\hline LC 7 & 95.19 & 4 & 94.15 & 4 & 0.5567 & 4 & 0.5607 & 4 & 0.1076 & 1 & 0.1076 & 1 \\
\hline LC 8 & 85.76 & 6 & 83.88 & 6 & 0.4350 & 5 & 0.4247 & 6 & 0.8802 & 6 & 0.8802 & 6 \\
\hline
\end{tabular}



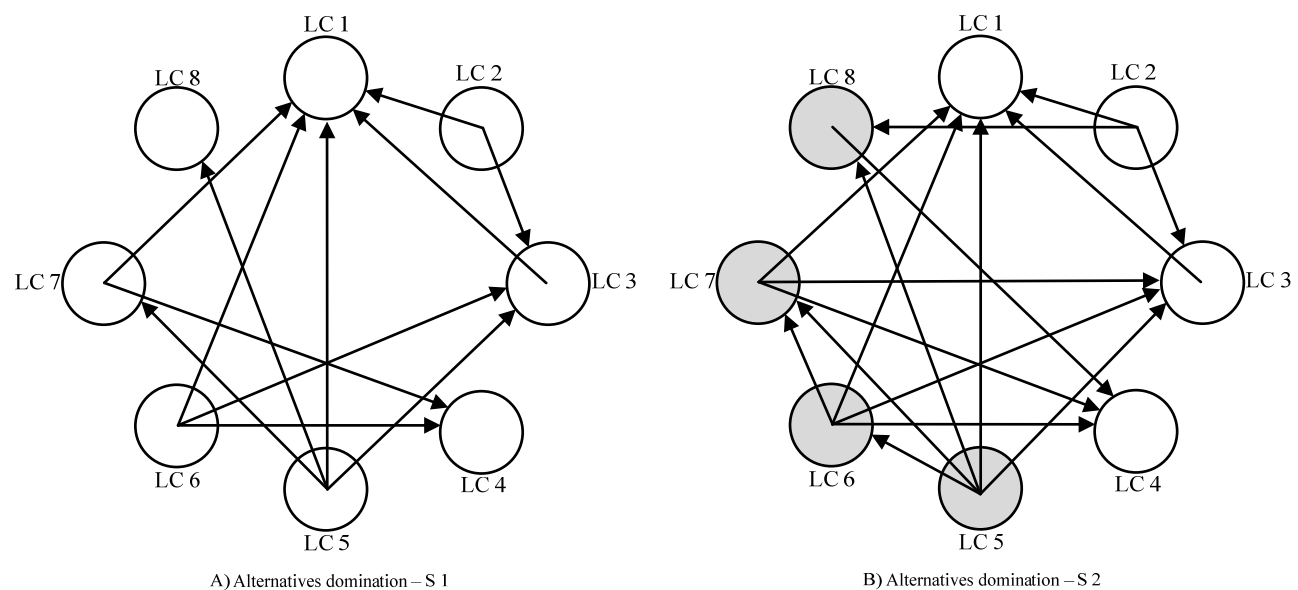

Figure 3. Solution Sensitivity to Changes in Measurement Scale by ELECTRE Method

other side, change in measurement scale does not affect the VIKOR method results.

\subsection{Results of sensitivity analysis of MDM methods to the change of criteria formulation}

Analyses shown in Tables A1-A7 show that certain methods do not keep consistency of results in case of formulation of criteria in two normatively equivalent ways. Shaded parts in Tables A1-A7 show inconsistent rankings.

In the first scenario (Table A1, Appendix A), inconsistency of rankings is demonstrated by COPRAS and TOPSIS methods, whilst methods VIKOR and ELECTRE maintain consistency of rankings. TOPSIS method experiences changes in rankings of the first and the last two alternatives. According to S1, ranking of the first two alternatives by TOPSIS method is LC $6>$ LC 2, whilst according to S2, the order is LC $2>$ LC 6 . According to S1, the order of the last two alternatives by TOPSIS method is LC $1>\mathrm{LC} 4$, whilst according to $\mathrm{S} 2$, the order is LC $4>\mathrm{LC} 1$.

Besides TOPSIS method, in the first scenario, significant inconsistency was demonstrated by COPRAS method as well. According to $\mathrm{S} 1$ at COPRAS method, the order of first six alternatives is LC $5>$ LC 6 $>$ LC $2>$ LC $7>$ LC $3>$ LC 8, whilst the application of S2 gives the order of LC $5>$ LC $2>$ LC $6>$ LC $7>$ LC $8>$ LC 3. Results show that COPRAS and TOPSIS methods significantly violate consistency of rankings with the change of criteria formulation (CFI case 1), whilst methods VIKOR and ELECTRE demonstrated stability of rankings.

In the second scenario (Table A2, Appendix A), inconsistency of rankings demonstrates only TOPSIS method, while the others maintain consistency. Just like in scenario 1 with TOPSIS method, changes of order in the first-ranked alternatives occur. Besides the first-ranked, alternatives LC 3 and LC 8 experience changes of ranking with TOPSIS method. By applying S1, we get that the order of the first six alternatives is $6>\mathrm{LC}$ $2>\operatorname{LC} 5>\operatorname{LC} 7>\operatorname{LC} 8>\operatorname{LC} 3$, while the application of $\mathrm{S} 2$ gives us the order of LC 2 $>$ LC $6>$ LC $5>$ LC $7>$ LC $3>$ LC 8 . In the second scenario, all the methods besides TOPSIS method demonstrated stability of rankings.

Similar to the first scenario, in the third 
scenario (Table A3, Appendix A), inconsistencies of rankings were demonstrated by methods COPRAS and TOPSIS. However, unlike the first scenario, inconsistency of COPRAS and TOPSIS methods was reduced. COPRAS and TOPSIS methods showed inconsistency in four rankings in the first scenario, and two inconsistencies in the third scenario. The rest of methods (VIKOR and ELECTRE) proved to be stable and maintained consistency.

In the fourth scenario (Table A4, Appendix A), COPRAS, TOPSIS and ELECTRE methods demonstrated inconsistency. COPRAS method demonstrated the greatest inconsistency (four rankings), whilst TOPSIS method had two inconsistent rankings. Inconsistency demonstrated by COPRAS method is identical as in CFI Scenario 1. It is necessary to emphasize that in this scenario at TOPSIS method, first-ranked alternatives demonstrate inconsistency.

Unlike the first three scenarios in which ELECTRE method demonstrated stability, in this scenario it experienced changes in the domination of alternatives (Figure $4 \mathrm{a}$ and $4 \mathrm{~b})$. Changes in domination of alternatives which occurred in scenario 4 are the same as the ones in Figure $3 \mathrm{a}$ and $3 \mathrm{~b}$ (MSI condition).

VIKOR method proved to be stable in this scenario and it maintained consistency. In scenarios 5, 6 and 7 (Tables A5-A7, Appendix A), the biggest inconsistency was demonstrated by TOPSIS method. In scenarios 5 and 7 , TOPSIS method demonstrated inconsistency in 5 rankings, while in scenario 6 , it demonstrated inconsistency in 6 rankings. In all three scenarios, TOPSIS method experiences changes in rankings of the first three alternatives. According to $\mathrm{S} 1$, the order of the first three alternatives is LC $6>$ LC $2>$ LC 5, whilst the application of $\mathrm{S} 2$ gives us the order of LC $5>$ LC $6>$ LC 2. Besides inconsistencies of first-ranked alternatives of TOPSIS method, it shows inconsistencies of alternatives on the fifth and sixth place in all three scenarios. This proves that TOPSIS method significantly violates consistency of rankings with the change of formulation of criteria.

COPRAS method demonstrates inconsistency in two rankings in scenarios 5 and 6, while in scenario 7, inconsistency appears in four rankings. However, it is necessary to emphasize that in COPRAS
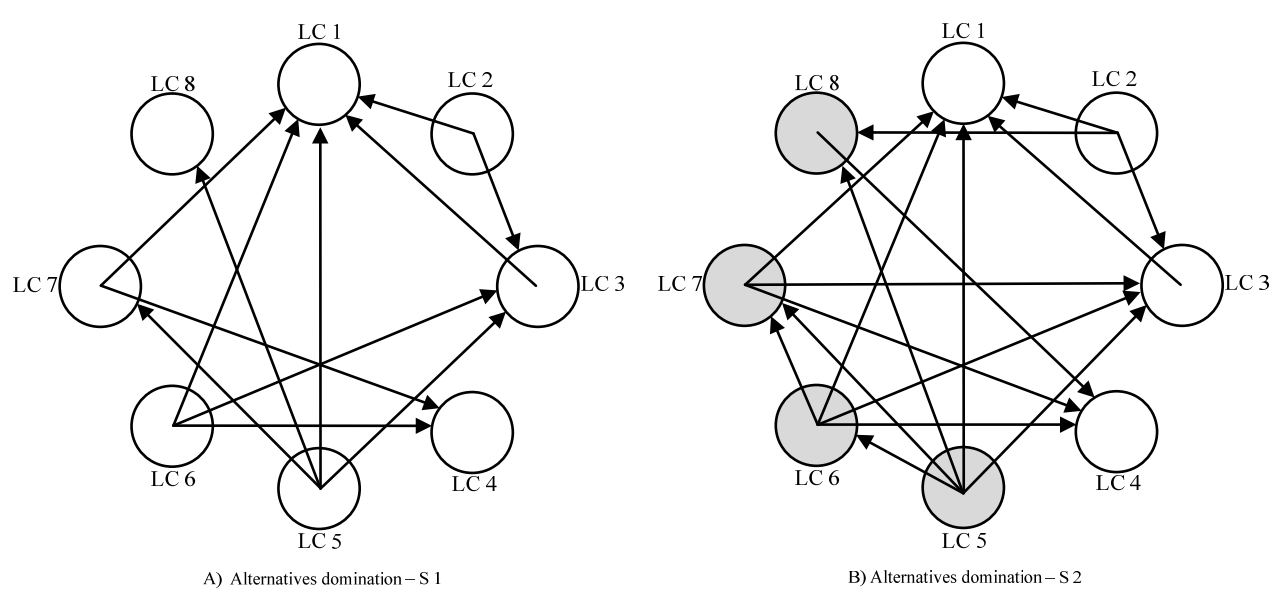

Figure 4. CFI Scenario 4 - Domination of Alternatives by ELECTRE Method 
method in scenarios 5, 6 and 7, there were no changes with the first-ranked alternative (LC 5). VIKOR and ELECTRE methods demonstrated stability of solutions in scenarios 5, 6 and 7 .

We can conclude that COPRAS, TOPSIS and ELECTRE methods do not satisfy MSI and CFI conditions. Unlike the listed methods, VIKOR method satisfies the CFI condition. Based on the demonstrated analyses, result systematization was conducted (Table 12).

In Table 12 symbol " $x$ " means that the method does not fulfill defined conditions of sensitivity, symbol $" \checkmark "$ means that the method fulfills defined conditions of sensitivity.

Based on results of sensitivity analysis (Table 12), it was proven that solutions obtained through VIKOR method were stable. ELECTRE method shows inconsistency in case of changes of measurement scale and in CFI Scenario 4. COPRAS method demonstrated inconsistency in seven out of eight cases (Table 12), whilst TOPSIS method showed inconsistency in all eight scenarios. It is necessary to emphasize that TOPSIS method experiences changes of first-ranked alternatives in six out of eight cases.

Since COPRAS, TOPSIS and ELECTRE methods violate the defined conditions, the order of alternatives which they recommend was not taken into account. The greatest stability was demonstrated by VIKOR method. Since the highest ranking alternative by VICOR method is LC 7, we can conclude that LC 7 is the optimal alternative and that VIKOR method offers the most stable solution.

\section{CONCLUSION}

In this work, we recommended a model for analysis of result consistency of MDM methods which is based on the analysis of change of results of rankings due to change of income parameters of the decision making model. Among the changes of income parameters, this model considers the change of weight coefficients of attributes, change of measurement scale of qualitative attributes and the change of the way we formulate attributes. In this work, testing of recommended model was demonstrated on the problem of selection of the optimal location of an LC. While the LC location selection was conducted, results obtained from the four MDM methods (COPRAS, TOPSIS, ELECTRE and VIKOR) were analyzed. Demonstrated model gives an answer to the question: which alternative ranking results should we accept as reliable

Table 12. Sensitivity Analysis of Methods to Changes of Measurement Scale and Criteria Formulation

\begin{tabular}{lcccc}
\hline \multirow{2}{*}{ Sensitivity Criteria } & \multicolumn{4}{c}{ MDM Methods } \\
\cline { 2 - 5 } & COPRAS & TOPSIS & ELECTRE & VIKOR \\
\hline MSI & $x$ & $x$ & $X$ & $\checkmark$ \\
CFI Scenario 1 & $x$ & $x$ & $\checkmark$ & $\checkmark$ \\
CFI Scenario 2 & $\checkmark$ & $x$ & $\checkmark$ & $\checkmark$ \\
CFI Scenario 3 & $x$ & $x$ & $\checkmark$ & $\checkmark$ \\
CFI Scenario 4 & $x$ & $x$ & $\checkmark$ & $\checkmark$ \\
CFI Scenario 5 & $x$ & $x$ & $\checkmark$ & $\checkmark$ \\
CFI Scenario 6 & $x$ & $x$ & $\checkmark$ & $\checkmark$ \\
CFI Scenario 7 & $x$ & $x$ & & $\checkmark$ \\
\hline
\end{tabular}


in cases when applying different MDM methods on the same problem with the same parameters offers mutually inconsistent solutions. The concept of proposed model is based on accepting results of the one MDM method whose results in the process of analysis demonstrate the greatest reliability under conditions of change of listed input parameters. Since the three conditions of reliability that were defined in this model are not the only conditions based on which MDM methods can be analyzed, the model can be upgraded by introducing new conditions, which are applied on another problem.

The results of application of the recommended model on the example of selection of the location of logistical center demosntrate that three (COPRAS, TOPSIS and ELECTRE0 out of four applied methods do not provide reliable results. Depending on the observed condition of reliability, the methods demonstrate smaller or greater deviations from initial solutions (initail ranking of alternatives). During the process of selecting the optimal method for ranking locations, from the aspect of stability of obtained results, VIKOR method proved to be the most reliable method. It is necessary to emphasize that results showed in section 5 refer only to the observed example and cannot be generalized. The recommended mode represents the general model for sensitivity analysis of MDM methods and therefore it is necessary to conduct sensitivity analysis of methods by scenarios defined in section 4 .

Finally, it is necessary to emphasize that MDM methods are just tools that recommend solutions to the decision makers. Some methods in certain situations provide better solutions than the others, but we should keep in mind that none of them is absolutely reliable. In accordance with that, the decision maker can make a decision based on his/her personal preferences following the application of multiple MDM methods and reliability analysis.

\section{References}

Ahari, R.M., \& Niaki, S.T.A. (2014). A hybrid approach based on locally linear neuro-fuzzy modeling and TOPSIS to determine the quality grade of gas welldrilling projects. Journal of Petroleum Science and Engineering, 114, 99-106.

Anojkumar, L., Ilangkumaran, M., \& Sasirekha, V. (2014). Comparative analysis of MCDM methods for pipe material selection in sugar industry. Expert Systems with Applications, 41, 2964-2980.

Awasthi, A., Omrani, H., \& Gerber, P. (2013). Multicriteria decision making for sustainability evaluation of urban mobility projects, CEPS/INSTEAD Working Paper No 2013-01, 1-31.

Bach, E., \& Bridy, A. (2013). On the number of distinct functional graphs of affine-linear transformations over finite fields, Linear Algebra and its Applications, 439, 1312-1320.

Barysiene, J. (2012). A multi-criteria evaluation of container terminal technologies applying the COPRAS-G method. Transport, 27 (4), 364-372.

Bottani, E., \& Rizzi, A. (2006). A fuzzy TOPSIS methodology to support outsourcing of logistics services. Supply Chain Management: An International Journal, 11 (4), 294-308.

Camparo, J. (2013). A geometrical approach to the ordinal data of Likert scaling and attitude measurements: The density matrix in psychology, Journal of 
Mathematical Psychology, 57, 29-42.

Chang, T.H. (2014). Fuzzy VIKOR method: A case study of the hospital service evaluation in Taiwan. Information Sciences, 271, 196-212.

Chang, C.H., Lin, J.J., Linc, J.H., \& Chiang, M.C. (2010). Domestic open-end equity mutual fund performance evaluation using extended TOPSIS method with different distance approaches. Expert Systems with Applications, 37 (6), 46424649.

Chen S., \& Liu, X. (2006). Factors and a Method of Selecting a Site for a Logistical Centre. Journal of Weinan Teachers College, 2, 20-23.

Corrente, S., Figueira, J., \& Greco, S. (2014). The SMAA-PROMETHEE method. European Journal of Operational Researsch, 239 (2), 514-522.

French, S. (1988). Decision theory - an introduction to the mathematics of rationality, Chrichster, Ellis Horwood Ltd.

Ghoseiri, K., \& Lessan, J. (2008). Location selection for logistic centres using a two-step fuzzy AHP and ELECTE method. Proceedings of the 9th Asia Pasific Industrial Engineering \& Management Systems Conference, Indonesia, 434-440.

Kaboli, A., Aryanezhad, M.B., \& Shahanaghi, K. (2007). A holistic approach based on MCDM for solving location problems. International Journal of Engineering Transactions A: Basics, 20 (3), 252-262.

Kahneman, D., \& Tversky, A. (1979). Prospect Theory: An Analysis of Decision under Risk, Econometrica, 47(2), 263-292.

Kahneman, D., \& Tversky, A. (1981). The Framing of Decisions and the Psychology of Choice, Science, 211 (4481), 453-458.

Kannan, D., Jabbour, A., \& Jabbour, C. (2014). Selecting green suppliers based on
GSCM practices: Using fuzzy TOPSIS applied to a Brazilian electronics company. European Journal of Operational Research, 233, 432-447.

Kelemenis, A., \& Askounis, D. (2010). A new TOPSIS-based multi-criteria approach to personnel selection. Expert Systems with Applications, 37, 4999-5008.

Kracka, M., Brauers, W.K.M., \& Zavadskas, E.K. (2010). Ranking heating losses in a building by applying the MULTIMOORA. Inzinerine EkonomikaEngineering Economics, 21 (4), 352-359.

Lai, M.C., Sohn, H.S., Tseng, T.L., \& Chiang, C. (2010). A hybrid algorithm for capacitated plant location problem. Expert Systems with Applications, 37 (12), 8599-8605.

Li, P., Qian, H., Wu, J., \& Chen, J. (2013a). Sensitivity analysis of TOPSIS method in water quality assessment: I. Sensitivity to the parameter weights. Environmental Monitoring and Assessment, 185, 2453-2461.

Li, P., Qian, H., Wu, J., \& Chen, J. (2013b). Sensitivity analysis of TOPSIS method in water quality assessment II: Sensitivity to the index input data. Environmental Monitoring and Assessment, 185, 2463-2474.

Liu, C.H., Tzeng, G.H., \& Lee, M.H. (2013). Improving metro-airport connection service for tourism development: Using hybrid MCDM models. Tourism Management Perspectives, 6, 95-107.

Liu, H.C., \& Wu, J. (2013). Ping LiAssessment of health-care waste disposal methods using a VIKOR-based fuzzy multicriteria decision making method. Waste Management, 33, 2744-2751.

Morteza, Y., \& Farokh-Payam, A. (2015). A comparative study on material selection of microelectromechanical systems 
electrostatic actuators using Ashby, VIKOR locating based on ANP-COPRAS-G and TOPSIS. Materials and Design, 65, methods - an empirical study based on Iran. 328-334.

Mulliner, E., Smallbone, K., \& Maliene, V. (2013). An assessment of sustainable housing affordability using a multiple criteria decision making method. Omega, 41, 270-279.

Opricović, S., \& Tzeng, G.H. (2004). Compromise solution by MCDM methods: A comparative analysis of VIKOR and TOPSIS. European Journal of Operational Research, 156 (2), 445-455.

Ou, C.-W., \& Chou, S.-Y. (2009). International distribution centre selection from a foreign market perspective using a weighted fuzzy factor rating system. Expert System with Applications, 36 (2), 17731782.

Pamučar, D., \& Ćirović, G. (2015). The selection of transport and handling resources in logistics centers using Multi-Attributive Border Approximation area Comparison. Expert Systems with Applications, 42 (6), 3016-3028.

Pavličić, D. (1997). Individual preferences and rational choice. Psychology, 1-2, 49-76.

Pavličić, D. (2002). Consistency of multiattribute analysis method choice, Economic annals, 155, 59-82.

Peng, Y., Kou, G., Wang, G., \& Shi, Y. (2011). FAMCDM: A fusion approach of MCDM methods to rank multiclass classification algorithms. Omega, 39, 677-689.

Rahmaniani, R., Saidi-Mehrabad, M., \& Ashouri, H. (2013). Robust capacitated facility location problem optimization model and solution algorithms. Journal of Uncertain Systems, 7 (1), 22-35.

Rezaeiniya, N., Zolfani, S.H., \& Zavadskas, E.K. (2012). Greenhouse International Journal of Strategic Property Management, 16 (2), 188-200.

Rodrigues, F.L.J., Osiro, L., \& Carpinetti, L.C.R. (2014). A comparation between Fuzzy AHP and Fuzzy TOPSIS methods to supplier selection. Applied Soft Computing, 21, 194-209.

Rogers, M., \& Bruen, M. (1998). Choosing realistic values of indifference, preference and veto thresholds for use with environmental criteria within ELECTRE. European Journal of Operational Research, 107, 542-51.

Shanian, A., \& Savadogo, O. (2006). TOPSIS multiple-criteria decision support analysis for material selection of metallic bipolar plates for polymer electrolyte fuel cell. Journal of Power Sources, 159 (2), 1095-1104.

Stevens-Navarro, E., Martinez-Morales, J.D., \& Pineda-Rico, U. (2012). Evaluation of Vertical Handoff Decision Algorightms Based on MADM Methods for Heterogeneous Wireless Networks. Journal of Applied Research and Technology, 10, 534-548.

Sun, M. (2012). A tabu search heuristic procedure for the capacitated facility location problem. Journal of Heuristics, 18 (1), 91-118.

Triantaphyllou, E. (2000). Multi-criteria decision making methods: A comparative study. Kluwer, Dordrecht.

Triantaphyllou, E., \& Lin, C-T. (1996). Development and evaluation of five fuzzy multiattribute decision-making methods. International Journal of Approximate Reasoning, 14 (4), 281-310.

Triantaphyllou, E., \& Mann, S.H. (1989). An Examination of the Effectiveness of Multi-Dimensional Decision-Making 


\title{
ВИШЕ-КРИТЕРИЈУМСКО ОДЛУЧИВАЊЕ: ПРИМЕР АНАЛИЗЕ ОСЕТЉИВОСТИ
}

\author{
Драган С. Памучар, Дарко Божанић, Аща Ранђеловић
}

\section{Извод}

У овом раду приказан је модел за оцену конзистентности резултата метода вишекритеријумског одлучивања (ВКО) и избор оптималне методе. Модел се заснива на анализи резултата метода ВКО односно, анализи промена у ранговима метода ВКО које настају услед промене улазних параметара. У предложеном моделу испитује се анализа осетљивости резулата метода ВКО на промену тежина критријума и конзистентност решења метода на промене мерне скале и начина формулације критеријума. У завршној фази модела врши се избор најповољније методе ВКО за решавање посматраног проблема и избор оптималне алтернативе. Модел је тестиран на примеру избора оптималне методе ВКО за одређивање локације логистичког центра. Приликом избора оптималне методе за решавање посматраног проблема разматране су методе "TOPSIS", “COPRAS", "VIKOR" и "ELECTRE". Метода "VIKOR" показала је највећу стабилност рангова и изабрана је као најпогоднија метода за рангирање локација логистичког центра.Резултати приказане анализе указују на осетљивост стандардних метода вишекритеријумског одлучивања, на критеријуме који су разматрани у овом раду. Зато је потребно да се, приликом избора оптималне методе вишекритеријумског одлучивања, узме у обзир стабилност разматране методе.

Кључнњ речи: Методе вишекритеријумског одлучивања, “TOPSIS", “COPRAS”, "VIKOR”, "ELECTRE"

Methods: A Decision-Making Paradox. Decision Support Systems, 5, 303-312.

Ustinovichius, L., Zavadskas, E.K., \& Podvezko, V. (2007). Application of a quantitative multiple criteria decision making (MCDM-1) approach to the analysis of investments in construction. Control and Cybernetics, 36 (1), 251-268.

Viteikiene, M., \& Zavadskas, E.K. (2007). Evaluating the sustainability of Vilnius city residential areas. Journal of civil engineering and management, 13 (2), 149-155.

Wang, S., \& Liu, P. (2007). The evaluation study on location selection of logistics centre based on fuzzy AHP and TOPSIS. International Conference on Wireless Communications, Networking and Mobile Computing, 3779-3782.

Wang, X., \& Triantaphyllou, E. (2008). Ranking irregularities when evaluating alternatives by using some ELECTRE methods. Omega, 36, 45-63.

Wang, Y.L., \& Tzeng, G.H. (2012). Brand marketing for creating brand value based on a MCDM model combining DEMATEL with ANP and VIKOR methods. Expert Systems with Applications, 39, 5600-5615.

Yang, J.L., Chiu, H.N., Tzeng, G.H., \& Yeh, R.H. (2008). Vendor selection by integrated fuzzy MCDM techniques with independent and interdependent relationships. Information Sciences, 178, 4166-4183.

Yu, O.-Y., Guikema, S.D., Briaud, J.-L., \& Burnett, D. (2012). Sensitivity Analysis for Multi-Attribute System Selection Problems in Onshore Environmentally Friendly Drilling (EFD). Systems engineering, 15 (2), 153-171.

Zare Mehrjerdi, Y., \& Nadizadeh, A. (2013). Using greedy clustering method to solve capacitated location-routing problem with fuzzy demands. European Journal of Operational Research, 229 (1), 75-84. 


\section{APPENDIX A}

Table A1. CFI Scenario 1 - Alternatives Ranking

\begin{tabular}{|c|c|c|c|c|c|c|c|c|c|c|c|c|}
\hline \multirow{2}{*}{ Alternatives } & \multicolumn{4}{|c|}{ COPRAS } & \multicolumn{4}{|c|}{ TOPSIS } & \multicolumn{4}{|c|}{ VIKOR } \\
\hline & $\mathrm{S} 1$ & & $\mathrm{~S} 2$ & & $\mathrm{~S} 1$ & & $\mathrm{~S} 2$ & & S1 & & $\mathrm{S} 2$ & \\
\hline LC 1 & 81.26 & 8 & 78.13 & 8 & 0.3871 & 7 & 0.3593 & 8 & 0.9600 & 7 & 0.9600 & 7 \\
\hline LC 2 & 97.74 & 3 & 98.78 & 2 & 0.6328 & 2 & 0.6591 & 1 & 0.5323 & 4 & 0.5323 & 4 \\
\hline LC 3 & 85.98 & 5 & 84.04 & 6 & 0.4339 & 6 & 0.4267 & 6 & 0.7636 & 5 & 0.7636 & 5 \\
\hline LC 4 & 81.57 & 7 & 79.25 & 7 & 0.3796 & 8 & 0.3654 & 7 & 0.9674 & 8 & 0.9674 & 8 \\
\hline LC 5 & 100.0 & 1 & 100.0 & 1 & 0.6039 & 3 & 0.6198 & 3 & 0.1717 & 2 & 0.1717 & 2 \\
\hline LC 6 & 97.96 & 2 & 97.50 & 3 & 0.6329 & 1 & 0.6415 & 2 & 0.3470 & 3 & 0.3470 & 3 \\
\hline LC 7 & 95.19 & 4 & 94.34 & 4 & 0.5567 & 4 & 0.5669 & 4 & 0.1076 & 1 & 0.1076 & 1 \\
\hline LC 8 & 85.76 & 6 & 85.29 & 5 & 0.4350 & 5 & 0.4736 & 5 & 0.8802 & 6 & 0.8802 & 6 \\
\hline
\end{tabular}

Table A2. CFI Scenario 2 - Alternatives Ranking

\begin{tabular}{|c|c|c|c|c|c|c|c|c|c|c|c|c|}
\hline \multirow{2}{*}{ Alternatives } & \multicolumn{4}{|c|}{ COPRAS } & \multicolumn{4}{|c|}{ TOPSIS } & \multicolumn{4}{|c|}{ VIKOR } \\
\hline & $\mathrm{S} 1$ & & $\mathrm{~S} 2$ & & $\mathrm{~S} 1$ & & $\mathrm{~S} 2$ & & $\mathrm{~S} 1$ & & $\mathrm{~S} 2$ & \\
\hline LC 1 & 81.26 & 8 & 81.27 & 8 & 0.3871 & 7 & 0.3920 & 7 & 0.9600 & 7 & 0.9600 & 7 \\
\hline $\mathrm{LC} 2$ & 97.74 & 3 & 97.73 & 3 & 0.6328 & 2 & 0.6366 & 1 & 0.5323 & 4 & 0.5323 & 4 \\
\hline LC 3 & 85.98 & 5 & 85.91 & 5 & 0.4339 & 6 & 0.4362 & 5 & 0.7636 & 5 & 0.7636 & 5 \\
\hline LC 4 & 81.57 & 7 & 81.50 & 7 & 0.3796 & 8 & 0.3855 & 8 & 0.9674 & 8 & 0.9674 & 8 \\
\hline LC 5 & 100.0 & 1 & 100.0 & 1 & 0.6039 & 3 & 0.6053 & 3 & 0.1717 & 2 & 0.1717 & 2 \\
\hline LC 6 & 97.96 & 2 & 97.96 & 2 & 0.6329 & 1 & 0.6350 & 2 & 0.3470 & 3 & 0.3470 & 3 \\
\hline $\mathrm{LC} 7$ & 95.19 & 4 & 95.14 & 4 & 0.5567 & 4 & 0.5616 & 4 & 0.1076 & 1 & 0.1076 & 1 \\
\hline LC 8 & 85.76 & 6 & 85.74 & 6 & 0.4350 & 5 & 0.4331 & 6 & 0.8802 & 6 & 0.8802 & 6 \\
\hline
\end{tabular}

Table A3. CFI Scenario 3 - Alternatives Ranking

\begin{tabular}{|c|c|c|c|c|c|c|c|c|c|c|c|c|}
\hline \multirow{2}{*}{ Alternatives } & \multicolumn{4}{|c|}{ COPRAS } & \multicolumn{4}{|c|}{ TOPSIS } & \multicolumn{4}{|c|}{ VIKOR } \\
\hline & S1 & & $\mathrm{S} 2$ & & S1 & & $\mathrm{S} 2$ & & $\mathrm{~S} 1$ & & $\mathrm{~S} 2$ & \\
\hline$\overline{\mathrm{LC}} 1$ & 81.26 & 8 & 77.10 & 7 & 0.3871 & 7 & 0.3678 & 7 & 0.9600 & 7 & 0.9600 & 7 \\
\hline LC 2 & 97.74 & 3 & 95.30 & 3 & 0.6328 & 2 & 0.6370 & 2 & 0.5323 & 4 & 0.5323 & 4 \\
\hline LC 3 & 85.98 & 5 & 85.81 & 5 & 0.4339 & 6 & 0.4952 & 5 & 0.7636 & 5 & 0.7636 & 5 \\
\hline LC 4 & 81.57 & 7 & 77.08 & 8 & 0.3796 & 8 & 0.3489 & 8 & 0.9674 & 8 & 0.9674 & 8 \\
\hline LC 5 & 100.0 & 1 & 100.0 & 1 & 0.6039 & 3 & 0.6355 & 3 & 0.1717 & 2 & 0.1717 & 2 \\
\hline LC 6 & 97.96 & 2 & 96.22 & 2 & 0.6329 & 1 & 0.6481 & 1 & 0.3470 & 3 & 0.3470 & 3 \\
\hline LC 7 & 95.19 & 4 & 94.28 & 4 & 0.5567 & 4 & 0.6009 & 4 & 0.1076 & 1 & 0.1076 & 1 \\
\hline LC 8 & 85.76 & 6 & 81.73 & 6 & 0.4350 & 5 & 0.3986 & 6 & 0.8802 & 6 & 0.8802 & 6 \\
\hline
\end{tabular}

Table A4. CFI Scenario 4 - Alternatives Ranking

\begin{tabular}{|c|c|c|c|c|c|c|c|c|c|c|c|c|}
\hline \multirow{2}{*}{ Alternatives } & \multicolumn{4}{|c|}{ COPRAS } & \multicolumn{4}{|c|}{ TOPSIS } & \multicolumn{4}{|c|}{ VIKOR } \\
\hline & $\mathrm{S} 1$ & & $\mathrm{~S} 2$ & & $\mathrm{~S} 1$ & & $\mathrm{~S} 2$ & & $\mathrm{~S} 1$ & & $\mathrm{~S} 2$ & \\
\hline $\mathrm{LC} 1$ & 81.26 & 8 & 76.74 & 8 & 0.3871 & 7 & 0.3922 & 7 & 0.9600 & 7 & 0.9600 & 7 \\
\hline LC 2 & 97.74 & 3 & 97.60 & 2 & 0.6328 & 2 & 0.6486 & 1 & 0.5323 & 4 & 0.5323 & 4 \\
\hline LC 3 & 85.98 & 5 & 82.71 & 6 & 0.4339 & 6 & 0.4491 & 6 & 0.7636 & 5 & 0.7636 & 5 \\
\hline LC 4 & 81.57 & 7 & 77.05 & 7 & 0.3796 & 8 & 0.3750 & 8 & 0.9674 & 8 & 0.9674 & 8 \\
\hline LC 5 & 100.0 & 1 & 100.0 & 1 & 0.6039 & 3 & 0.6380 & 3 & 0.1717 & 2 & 0.1717 & 2 \\
\hline LC 6 & 97.96 & 2 & 96.87 & 3 & 0.6329 & 1 & 0.6423 & 2 & 0.3470 & 3 & 0.3470 & 3 \\
\hline LC 7 & 95.19 & 4 & 93.29 & 4 & 0.5567 & 4 & 0.5724 & 4 & 0.1076 & 1 & 0.1076 & 1 \\
\hline LC 8 & 85.76 & 6 & 83.20 & 5 & 0.4350 & 5 & 0.4572 & 5 & 0.8802 & 6 & 0.8802 & 6 \\
\hline
\end{tabular}


Table A5. CFI Scenario 5 - Alternatives Ranking

\begin{tabular}{|c|c|c|c|c|c|c|c|c|c|c|c|c|}
\hline \multirow{2}{*}{ Alternatives } & \multicolumn{4}{|c|}{ COPRAS } & \multicolumn{4}{|c|}{ TOPSIS } & \multicolumn{4}{|c|}{ VIKOR } \\
\hline & $\mathrm{S} 1$ & & $\mathrm{~S} 2$ & & $\mathrm{~S} 1$ & & $\mathrm{~S} 2$ & & $\mathrm{~S} 1$ & & $\mathrm{~S} 2$ & \\
\hline $\mathrm{LC} 1$ & 81.26 & 8 & 73.15 & 8 & 0.3871 & 7 & 0.3745 & 7 & 0.9600 & 7 & 0.9600 & 7 \\
\hline $\mathrm{LC} 2$ & 97.74 & 3 & 95.39 & 2 & 0.6328 & 2 & 0.6480 & 3 & 0.5323 & 4 & 0.5323 & 4 \\
\hline LC 3 & 85.98 & 5 & 82.30 & 5 & 0.4339 & 6 & 0.4930 & 5 & 0.7636 & 5 & 0.7636 & 5 \\
\hline LC 4 & 81.57 & 7 & 73.15 & 7 & 0.3796 & 8 & 0.3481 & 8 & 0.9674 & 8 & 0.9674 & 8 \\
\hline LC 5 & 100.0 & 1 & 100.0 & 1 & 0.6039 & 3 & 0.6587 & 1 & 0.1717 & 2 & 0.1717 & 2 \\
\hline LC 6 & 97.96 & 2 & 95.18 & 3 & 0.6329 & 1 & 0.6517 & 2 & 0.3470 & 3 & 0.3470 & 3 \\
\hline LC 7 & 95.19 & 4 & 92.46 & 4 & 0.5567 & 4 & 0.6015 & 4 & 0.1076 & 1 & 0.1076 & 1 \\
\hline LC 8 & 85.76 & 6 & 79.13 & 6 & 0.4350 & 5 & 0.4289 & 6 & 0.8802 & 6 & 0.8802 & 6 \\
\hline
\end{tabular}

Table A6. CFI Scenario 6-Alternatives Ranking

\begin{tabular}{|c|c|c|c|c|c|c|c|c|c|c|c|c|}
\hline \multirow{2}{*}{ Alternatives } & \multicolumn{4}{|c|}{ COPRAS } & \multicolumn{4}{|c|}{ TOPSIS } & \multicolumn{4}{|c|}{ VIKOR } \\
\hline & $\mathrm{S} 1$ & & $\mathrm{~S} 2$ & & $\mathrm{~S} 1$ & & $\mathrm{~S} 2$ & & S1 & & $\mathrm{S} 2$ & \\
\hline $\mathrm{LC} 1$ & 81.26 & 8 & 75.68 & 7 & 0.3871 & 7 & 0.3995 & 6 & 0.9600 & 7 & 0.9600 & 7 \\
\hline $\mathrm{LC} 2$ & 97.74 & 3 & 94.22 & 3 & 0.6328 & 2 & 0.6302 & 3 & 0.5323 & 4 & 0.5323 & 4 \\
\hline LC 3 & 85.98 & 5 & 84.08 & 5 & 0.4339 & 6 & 0.5042 & 5 & 0.7636 & 5 & 0.7636 & 5 \\
\hline LC 4 & 81.57 & 7 & 74.74 & 8 & 0.3796 & 8 & 0.3613 & 8 & 0.9674 & 8 & 0.9674 & 8 \\
\hline LC 5 & 100.0 & 1 & 100.0 & 1 & 0.6039 & 3 & 0.6508 & 1 & 0.1717 & 2 & 0.1717 & 2 \\
\hline LC 6 & 97.96 & 2 & 95.57 & 2 & 0.6329 & 1 & 0.6477 & 2 & 0.3470 & 3 & 0.3470 & 3 \\
\hline $\mathrm{LC} 7$ & 95.19 & 4 & 93.15 & 4 & 0.5567 & 4 & 0.6009 & 4 & 0.1076 & 1 & 0.1076 & 1 \\
\hline LC 8 & 85.76 & 6 & 79.93 & 6 & 0.4350 & 5 & 0.3942 & 7 & 0.8802 & 6 & 0.8802 & 6 \\
\hline
\end{tabular}

Table A7. CFI Scenario 7 - Alternatives Ranking

\begin{tabular}{|c|c|c|c|c|c|c|c|c|c|c|c|c|}
\hline \multirow{2}{*}{ Alternatives } & \multicolumn{4}{|c|}{ COPRAS } & \multicolumn{4}{|c|}{ TOPSIS } & \multicolumn{4}{|c|}{ VIKOR } \\
\hline & $\mathrm{S} 1$ & & $\mathrm{~S} 2$ & & S1 & & $\mathrm{S} 2$ & & $\mathrm{~S} 1$ & & $\mathrm{~S} 2$ & \\
\hline LC 1 & 81.26 & 8 & 72.99 & 7 & 0.3871 & 7 & 0.3778 & 7 & 0.9600 & 7 & 0.9600 & 7 \\
\hline LC 2 & 97.74 & 3 & 95.25 & 2 & 0.6328 & 2 & 0.6506 & 3 & 0.5323 & 4 & 0.5323 & 4 \\
\hline LC 3 & 85.98 & 5 & 82.14 & 5 & 0.4339 & 6 & 0.4945 & 5 & 0.7636 & 5 & 0.7636 & 5 \\
\hline LC 4 & 81.57 & 7 & 72.75 & 8 & 0.3796 & 8 & 0.3524 & 8 & 0.9674 & 8 & 0.9674 & 8 \\
\hline LC 5 & 100.0 & 1 & 100.0 & 1 & 0.6039 & 3 & 0.6595 & 1 & 0.1717 & 2 & 0.1717 & 2 \\
\hline LC 6 & 97.96 & 2 & 95.20 & 3 & 0.6329 & 1 & 0.6529 & 2 & 0.3470 & 3 & 0.3470 & 3 \\
\hline $\mathrm{LC} 7$ & 95.19 & 4 & 92.48 & 4 & 0.5567 & 4 & 0.6044 & 4 & 0.1076 & 1 & 0.1076 & 1 \\
\hline LC 8 & 85.76 & 6 & 79.12 & 6 & 0.4350 & 5 & 0.4277 & 6 & 0.8802 & 6 & 0.8802 & 6 \\
\hline
\end{tabular}

